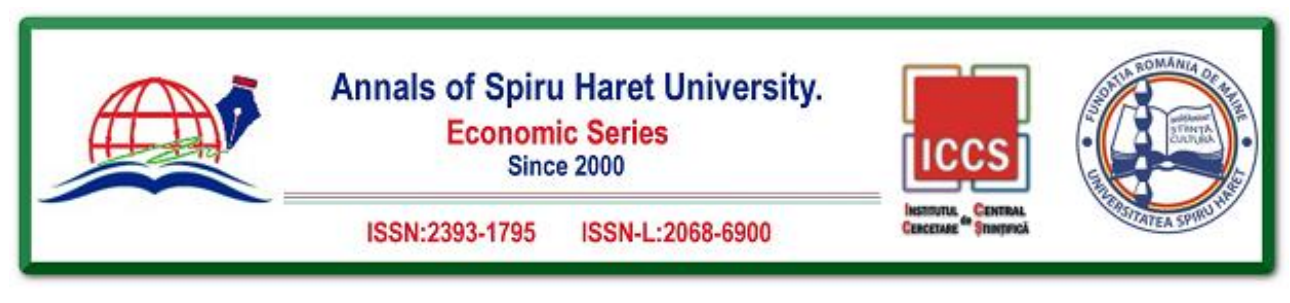

Issue 3/2018

\title{
ASPECTS CONCERNING THE COMPETITION OF BUSINESS OPERATORS \\ IN THE CONTEMPORARY BUSINESS ENVIRONMENT
}

\author{
Roxana ȘTEFĂNESCU \\ Spiru Haret University, Faculty of Legal, Economic and Administrative \\ Sciences, Brașov, Romania, Email: roxanstefanescu72@yahoo.com
}

How to cite: ŞTEFĂNESCU, R. (2018). "Aspects Concerning the Competition of Business Operations in the Contemporary Business Environment." Annals of Spiru Haret University. Economic Series, 18(3), 6979, doi: https://doi.org/10.26458/1835

\begin{abstract}
The competitive, ethical and legal attitude is a powerful element in increasing business development rhythm, but if it is guided towards the level of sublegal and the hits applied to competitors, then it turns into an anti-business, anti-development, anti-cohabitation, anti-productive environment.

The competitive, ethical and legal environment is beneficial for economic activity and social development.

Regardless of the form in which it takes place, business competition is complex in nature, including the development environment, resources, methods, contestants and competitors, directions, market shares, factors and locations.

Competitive complexity includes cultural factors, behaviours, promotional policies, regularities and morality, conjectures and recessions, personnel recruitment and picking up, distribution opportunities and facilities, complex and indispensable utilities, sharing human resources, energy, financial and material resources, policies of selection, cooperation, counteraction, annihilation or removal, procurement policies, dominance in areas or market shares, ingenuity, new products and services, investments and financial availability, capabilities of organization, of presentation, demonstration, of keeping the relations with the consumers.
\end{abstract}

Keywords: competition; aggressiveness; rivalry; market; competitive environment; participants in the competitive environment.

JEL Classification: $\mathrm{M}_{10}, \mathrm{M}_{16}$ 


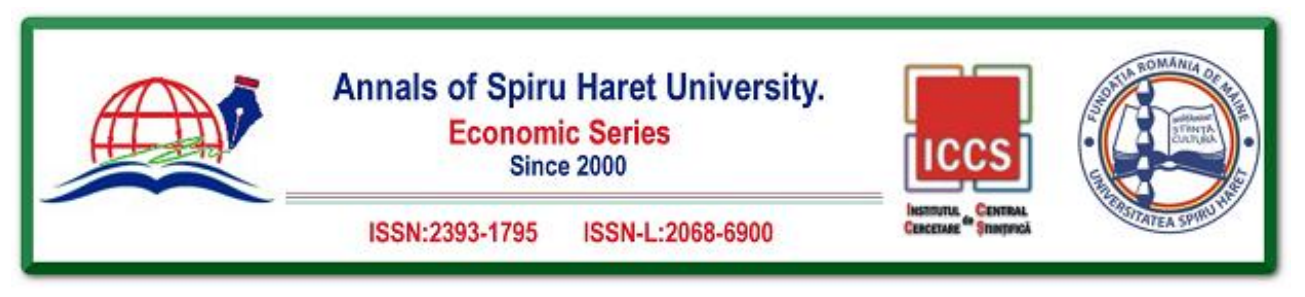

\section{Issue 3/2018}

\section{Introduction}

Competition represents the fundamental characteristic of the business environment and materializes in the confrontation of the business operators on the market.

The competition is, therefore, a direct race, linked to the distribution of the market shares, whose aggressiveness is full growing.

Under the conditions of the business environment development, there is an intensification of the aggressive nature of the competition, in close connection with the possibilities of the competitors and their abilities of assimilation and processing of information: collection, storage, analysis, intuition, predictability capacity, precision, fairness and rapidity of decision making. [Ștefănescu, 2014a]

An important factor on which the aggressiveness of competition depends is given by the market share where it is carried out (dominant, with products of general interest, with strict necessity services, with state-of-the-art technologies, fashion products, with time conditioned interest products, seasonal or events related products), by the competitors' or contestants' images (professionalism, soundness, opportunity, quality of products and services, dominant position, etc.), by their behavioural characteristics (adaptability, flexibility, sincerity), the size and the speed of development of the businesses.

The contestants' rivalry can be of aggressive nature, with undermining and finding fault with each other, or can be beneficial in terms of their differentiation through quality, advertising, utility, warranty, opening, improvement, etc.

The intensity of market competition in the business environment depends on the number and power of the competitors, the level of costs and sales, the complementarity of products and services, recession, inflation or economic growth.

\section{Structure of the Competitive Environment}

Concerning the structure of the competitive environment, the following fundamental approaches are highlighted:

- The cooperative approach consists of a common activity to achieve objectives of mutual interest; within the cooperative approach, the main manifestation is represented by the cooperation based on the harmonization of capabilities, resources and actions.

- The competitive approach represents elements of competition and partition corresponding to mutually recognized capabilities and resources; competitiveness does not exclude either cooperation based on hierarchical values or the competition 


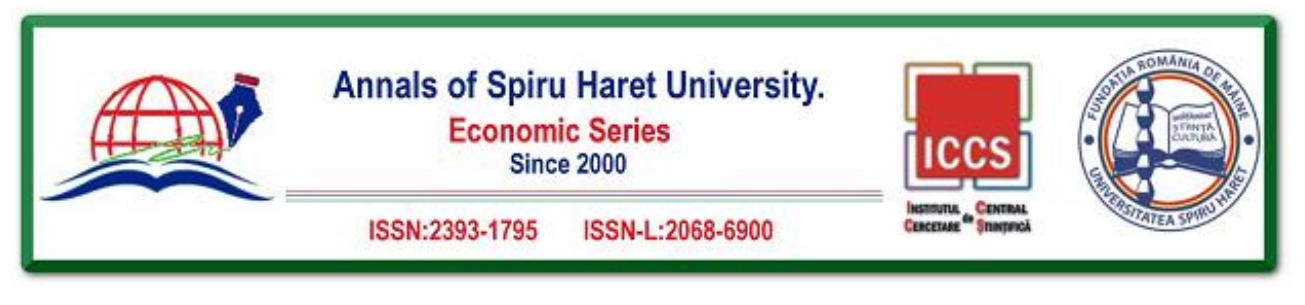

Issue $3 / 2018$

based on principles and tactics analysis within teams to prepare for competitive confrontation.

- The contest approach is based on confrontation, legality and ethics, if it is business spirit oriented, or on direct confrontation and "bloody" exploitation of the elements of sub-domination, lack of solutions, time pressure, doing business with any consequence (last solution), weaknesses, revenge, sabotage, bankruptcy, market blows, or ignorance, if you seek to win at any price.

Among the competitors in the competitive environment, the closest to a cooperative attitude are allies, common interest groups, intermediaries, as well as representative offices of the authorities that pursue social, equilibrium or environmental goals.

The competitive approach is usually established between the organizations that have been doing business for a long time, between privileged suppliers and distributors, between shareholders who have shared fields or areas of influence. The competition does not put a brake to the rhythm of businesses, but gives them some stability and security. Competitors rely on each other against unfair competition and associate in organizations or interest groups to defend or give them a certain power of representation. Technological, quality, opportunity, and efficiency competition is beneficial and is part of an emulation for the competitor, beneficiary, and business environment. [Ștefănescu, 2014b]

We will further use, in the above-shown meaning, the wording competitive business environment.

Concerning the relation between competitors and products, competition may be:

- Direct, on the same types of products and market shares, including organizations offering the same kind of products and services; however, direct competition includes also aspects related to quality, price, distribution, service, facilities of use and purchase, maintenance, development, improvement, etc.;

- Indirect, developed in the same utilities market share, including organizations offering variants of products, but also surrogates, counterfeits, etc.; indirect competition, seemingly less conflictual, is particularly fierce, being carried out without agreement, sharing or cohabitation.

A special place in the relation between the competitors is the business in the virtual environment, which is regarded as a third category virtual competition. However, considering that this type of competition differs from the others by the nature of the business environment and by the negotiation and purchase space only, we consider that it does not change relations, attitudes and competitors and therefore cannot be included as a separate entity. 


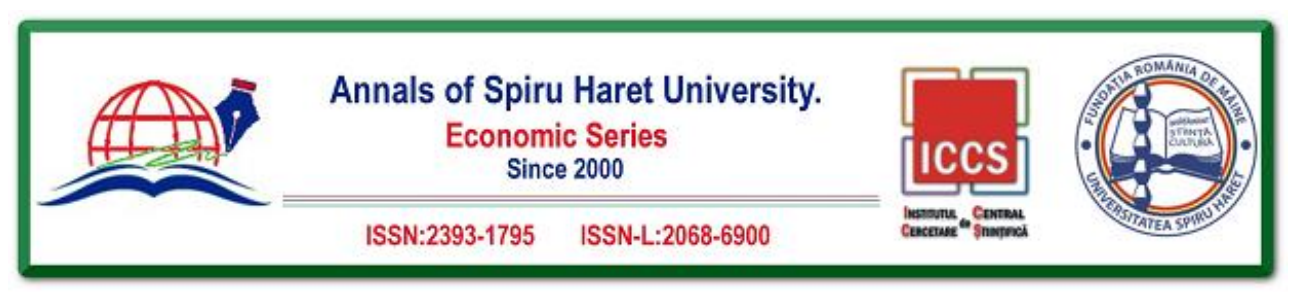

\section{Issue 3/2018}

The Market represents the environment in which competition takes place, not only for products and customers, but also for technologies, strategies, policies, actions, in other words the cultural framework of the business.

The Resources represent particularly active elements of competition and include personnel, finances, energy, matters and materials.

The Competitors encompass the full range of business actors, both active and passive.

The directions of the competition are considered to be defining in the structure of the market, hence the business environment, and in its division per contestants, competitors and consumers. The directions represent both specialization elements and direct or indirect action areas.

The Factors that influence the market are defining in the behaviour and orientation of competitors and may be favouring or disadvantaging it.

The segments represent competition environments that may be differentiated according to zonal or global nature, but also according to types of products and services or to competitive environment (real or virtual).

In a competitive environment, the threats are grouped into segments (crimes, domination, recession, unfair competition, market saturation, lack of utilities, etc.), while vulnerabilities depend on poor organization, inefficient management, inability, conservatism, over-reliance, bad placements, unfair relations, harmful contracts, unexploited facilities, no technology, lack of information, informational suffocation, poor information processing, low quality, negative behaviours, untrained and uninterested personnel, etc.

2. Aspects concerning the types of behaviour of the market players within the competitive environment

Alongside the uncertainties that govern the competitive environment (utilities, costs, resources, decisions, transactions, values, profits, etc.), the uncertainty of the behaviour of market players must be highlighted.

Every business is characterized by an accentuated uncertainty and, as such, the training of the players must be appropriate. The objective, the resources, the strategy, the business plan, the team and the type of behaviour are elements that cannot be left to chance.

The idea of dealing with opportunistic type of business is not only detrimental, but it represents a vulnerability, often insuperable for the organization. 


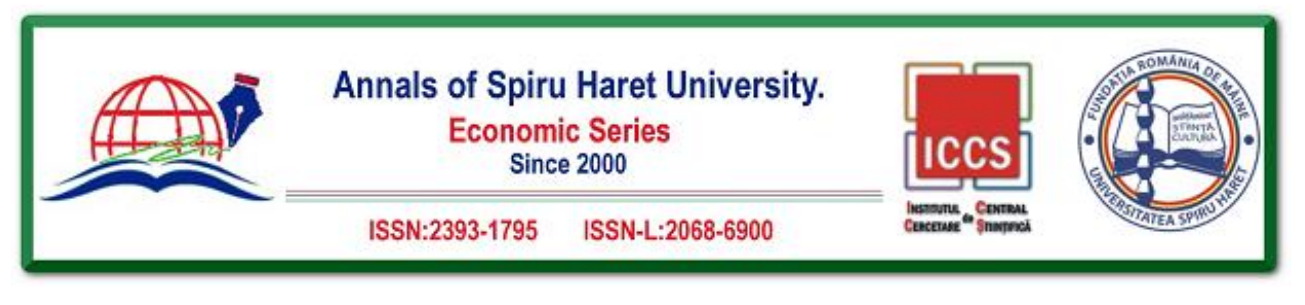

Issue $3 / 2018$

Analyzed in terms of the ratio of their size given by the turnover, profit, personnel, production, number of locations, areas of action, importance of the products and services, etc. and the market share they hold [Petrova, 2015], the competitors in the business environment may be grouped into four categories:

- The new entrants are small organizations, with small market shares that either have just entered the market or have a singular place on the market for a small group of products or services; these new entrants to the market can be particularly active in the meaning that they can impose high-yielding technologies, products and services with surprise utilities, highly skilled personnel, special methods of management, bidding, purchasing or presenting, or rapidly operating breaks between segments, of misunderstandings between the competitors or contestants; they may also practice low pricing or intimidation policies; the tendency of new entrants is to become conservative but, depending on strategies and successes, they may disappear or may transform in vulnerabilities, aggressors or conservatives.

- The organizations with vulnerabilities are small organizations which, by various methods, have been imposed on the market and gained an appreciable share; if they do not solve the problem of resources and consumer relations, they may quickly disappear through bankruptcy or absorption, or they may be transformed, due to the accumulation of resources, into conservatives.

- The firms with aggressive behaviour are large organizations which, although they have resources and represent a strong economic force, have a small market share either due to a fall, for various external or internal reasons, or are in times of expansion and they are looking for market; in both cases, these organizations have aggressive, conflictual behaviour, seeking to escape or penetrate the market at all costs; however, the aggressive behaviour of these organizations may be of a shorter or longer duration, depending on their tendency to turn into conservatives or firms with vulnerabilities.

- The conservative firms are large organizations with significant market shares; the name of conservatives is not appropriate for the behaviour, but only for the position, these organizations leading an active policy to preserve or improve their place and market share; the domination of these organizations is materialized by high-yielding technologies, a good organizing, they have experience, resources, financial standing, reputation, are market leaders, have products, services or utilities, well-developed sales networks and ensure great facilities for customers and collaborator; the position of conservatives, rather of seniors, is obtained hard and is kept even harder. 


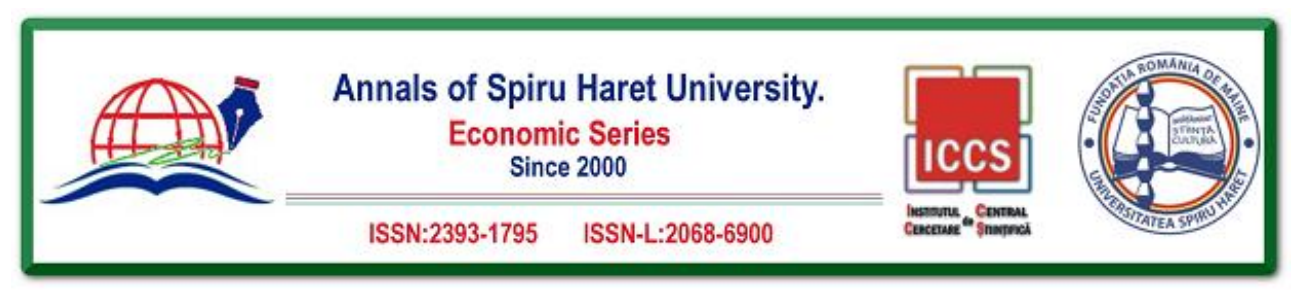

\section{Issue 3/2018}

The new contestants and competitors are of particular importance in keeping the market rhythm, while conservatives contribute, especially, to maintaining stability. If the remaining of the conservatives depends mainly on their behaviour, adaptability and flexibility, the penetration of new competitors is also conditioned by entry barriers aimed at:

- The economic size of production and sales over which profit can be achieved;

- Differentiating the quality or utility of new products and services;

- The minimum capital necessary to enter into business on the market;

- The cost of change and integration;

- The cost of learning and adaptation;

- The cost of communication channels.

The player-environment relation is a variable that must be managed in such a way as to have a good influence on the relations of the competition, identifying the opportunities, but also the threats and vulnerabilities of the respective organization. The evaluation criteria that can be used to manage the relationship are:

- The threats of the business environment that may influence the performance of the organization and the stability of their weight in the relation.

- The performance of the organization, which may create the benefits of dominating the contestants and stimulating the competitors.

-The vulnerabilities of the organization in the competitive relation and the possibilities of counteracting the threats and reducing the vulnerabilities.

-Determining the rationally assumed risk in the business, globally and in the directions of action.

Depending on the conclusions of the analysis of these assessment criteria, the organization needs to reformulate or adapt concerning:

- Increasing market share;

- Improving the quality of products and services;

- Improving the image;

- Efficiency of management and actions;

- Improving the collection and processing of information about competitors;

- Modelling and simulating future businesses;

- Training the negotiation teams;

- Improving maintenance, perfecting and opening capabilities. 


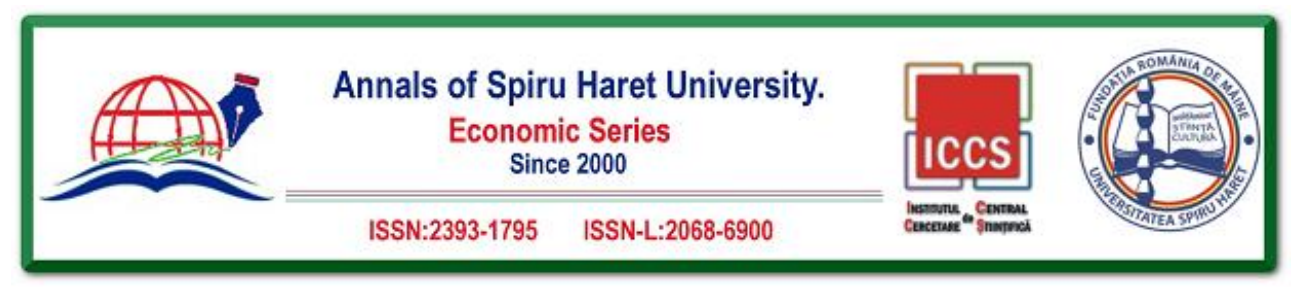

Issue 3/2018

\section{Elements determining the influence of the competitive behaviour}

In the business environment - competitive environment - there are two groups of factors that decisively influence the competitive behaviour:

- Those who watch the competitive climate;

- The competitive construction.

* The competitive climate represents those elements of the business environment that contribute to the determination of the competitors' behaviour in business. The climate refers to the general way of perceiving competitive relations, market manifestations, and the opportunities for players to negotiate and conclude businesses.

Among the elements that influence the competitive environment, we only highlight the following:

$\checkmark$ The legal business environment represented by the laws, norms, decisions, standards, codes, traditions and morality of the environment;

$\checkmark$ The size of the market and its orientation on strategic directions or those targeting profit;

$\checkmark$ Market evolution trends and business profitability, dependent on mature or insufficiently organized structures, new groups of producers, traders and consumers, competitive adaptability, their aggressive, penetrating or cooperative behaviour, trends of increase or decrease profitability;

$\checkmark$ The fields of cooperation, production, compensation, of substituting lack of products and services, relocation to other segments or market directions.

In assessing the importance of the competitive climate in the behaviour of the organizations, account must be taken of the fact that all organizations are functionally integrated subsystems in the business environment, and under these circumstances the relations between the organizations and the environment are extremely important. All these links contribute decisively to the establishment of business strategies of organizations and thus their behaviour in the environment, both generally and specifically [Ștefănescu, 2014a].

An important component for an organization, its relations with the environment, is the organization's dependence of resources. Depending on the trend of information and resources, and especially the correlation between them, the organization needs to shape its behaviour according to strategies of making more efficient the business actions, equal at least to the dynamics of the business environment or to change its strategy and hence its behaviour based on informational and resource constraints. 


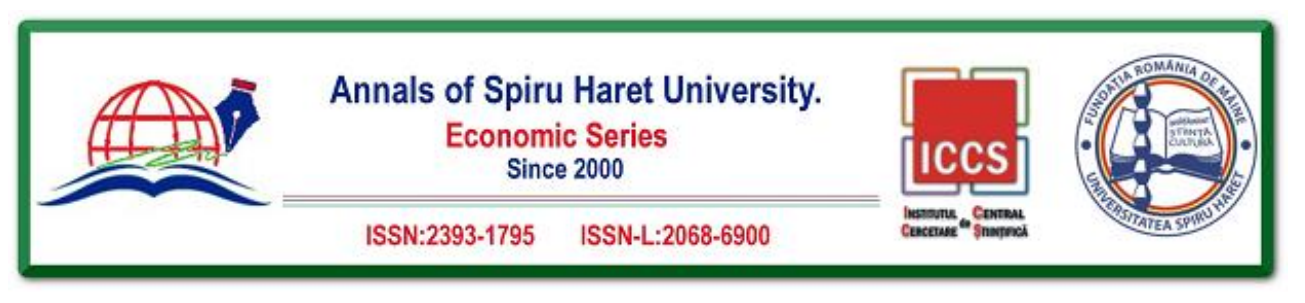

\section{Issue 3/2018}

Depending on the potential and organizational capabilities, the organizations need to act fast to change and adapt their behavioural strategies, but also to modify the environment so as to favour their step to make the business more efficient.

The active behaviour is often accompanied by success, while the expectant or non-stimulating behaviour in the environment economy is particularly damaging and may turn into an acute vulnerability of the organization.

* The competitive construction represents the way of structuring, with the idea of favouring the competition of both the business environment and of the organizations as its subsystems. The competitive construction may be a natural result of the competition in the business environment, but also a consequence of a strategy that aims to increasing market share and make business more efficient.

The competitive construction aims at [Ștefănescu, 2014b]:

$\checkmark$ Organizing market shares and organizations so as to favour value exchanges;

$\checkmark$ The price mechanism corresponding to the value of the products and services that are the subject of business;

$\checkmark$ The legitimacy favouring moral behaviour in business;

$\checkmark$ The security of the values that are the subject of business;

$\checkmark$ The mobility in business objectives and methods;

$\checkmark$ The motivation oriented towards achieving the objectives;

$\checkmark$ Adapting to the new requirements;

$\checkmark$ The correctness of the correlation of the business objectives with the objectives of the organizations.

Organizing the business environment must be directed towards meeting the needs of clients (consumers) and ensuring the supply, production and distribution conditions for suppliers (producers). A flexible construction of the business environment ensures both the satisfaction of clients' needs, and also the cultivation of their interests, satisfaction, advantageous value exchanges, increasing the utility of products and services launched on the market. The precise and efficient organizing favours a civilized behaviour based on respect for values and competitors.

The achievement of business objectives is also given by the circulation of information, the substantiation of decisions and the opportunity to apply them, which represent important components of the organizational management.

"The most of the management decisions are taken under the influence of external and internal environmental constraints. As the environment is constantly changing and the information is not always complete and available, management decisions can be made in certain, uncertain and risky conditions" [Negulescu, 2014]. 


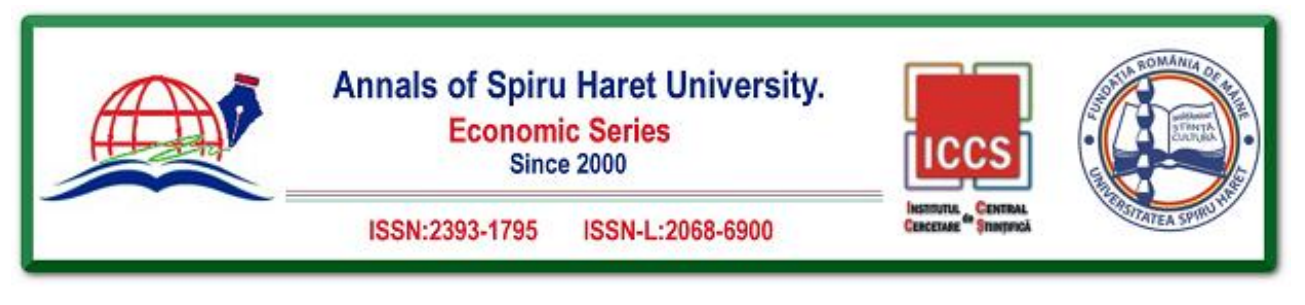

Issue 3/2018

The organizational structures appropriately established ensure elaborating and implementing strategies based on environmental, relational and correlational assessments, objectification of actions and evaluation of own successes.

An efficient organization must take into account the performance of functional relations, the correct use of resources and the legal framework for stock exchanges.

The price mechanism plays an important role in business, both in organizing area and in their objectivising, as well as in the correct evaluation of the values transacted. The price mechanism must be particularly flexible and include the full range of payment methods and facilities (classic, electronic, discounts, rebates, promotional prices, bonuses, etc.).

The legitimacy favouring the moral behaviour in business must ensure respect for the values and of all competitors and traders and to remove the tendencies to favour unfair conjectures, monopoly and conflictual aggression, unrealistic prices, of promoting surrogates, counterfeit products and services, or party behaviour.

The mobility of business goals and methods of carrying out the business represent an important quality of a mature organization with rational experience and behaviour. Isolation or freezing of methodologies represents a major organizing vulnerability and the consequence of narrow thinking such as "let it go as it went." At the same time, change for the sake of change may be a behavioural failure. Experience has to be cultivated, valued and used, but adapted and shaped according to the specificities of each business. No strategy or business plan guarantees success if they are not tailored and up-to-date according to the concrete development of the business. Consequently, much less a strategy or an old plan may be successfully used.

The elements that fundamentally determine the mobility are environmental changes (legislative, organizational, relational, competitive, etc.), conditions for selling or purchasing products and services, ways and timings of payment, negotiation, utilities and opportunities.

A common element of the two sets of factors is represented by ethics or morality of business. Max Weber shows that economic interests and moral norms coincide and govern human activity.

Ethics and professional activity are the fruit of a vocation that urges to a similar action to what you want from a partner. The respect for business must be based on the recognition of the value of the competitor and of the rational.

The relation between morality and market economy depends on political organizing, territorial administration, structure and objectives of the other organizations, business culture and legality. 


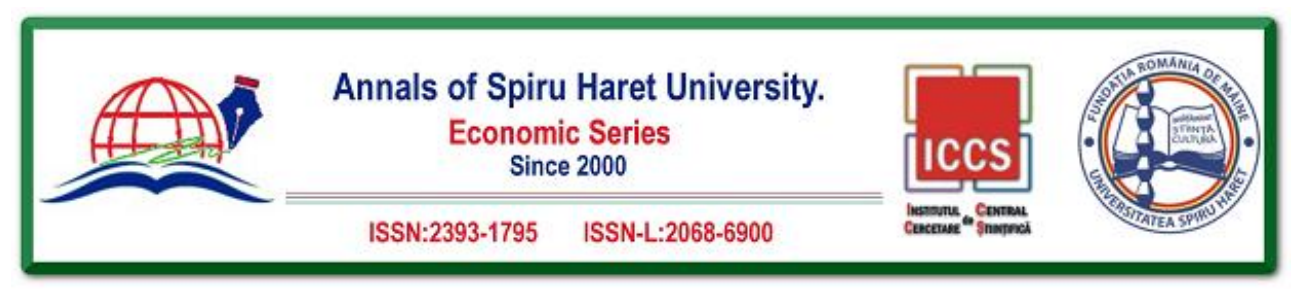

\section{Issue 3/2018}

Essentially, morals represent the application of principles and skills to facts of life under the observance of good, duty, responsibility, dignity, and equality of chances. Egoism, licit earning, corruption, dishonesty, deception, breach of the given word, disrespect are immoral categories which existence in business cancels the essence the exchange of values.

Another aspect that has to be considered is "the conflict of interests: situation of incompatibility in which a person is having a personal interest that influences the impartiality and the objectivity of its activities in evaluation, monitoring, realisation and reporting the research and development activities" [Negulescu \& Doval, 2012].

The ethical value of the business must be recorded through normative and deontology provisions, based on the mutual respect of competitors (business partners) and the values traded and obtained.

\section{Conclusions}

It is very important for the organizations, during the period of establishing the objectives, to use in depth studies and scientific analyzes of the products and services they place on the market. On this basis, strategic options and required resources will be identified as main vectors in achieving the goals, identifying the strengths - opportunities - and the weaknesses - vulnerabilities. However, the complexity of the international environment may be confronted by implementing the best suitable organizational change strategies and by continuous adaptation to changing of the complex global environment [Doval, 2016].

In the confrontation between the competition players, each of them will act specifically depending on their own interests, resources and capabilities, trying to attract as much as possible of the profit of the market and to harmonize their interests in supplying products and services at the lowest prices, with the most significant results.

It is also very important that after every successful business or not, the organization should analyze its strategy, plan, actions, results and methods of achieving goals over all horizons of time (long, medium or immediate) [Petrova \& Nichev, 2012].

A particular problem of the competition and contest climate is the relation between buyers (consumers) and suppliers (producers). This relation must maintain a procedural equilibrium and to be carried out in a safe climate.

The relation is balanced if stability between demand and offer, utility and quality, preferences and diversity is ensured, and it is unbalanced towards the buyers if the offer is higher and the utility and adaptability are lower or towards the 


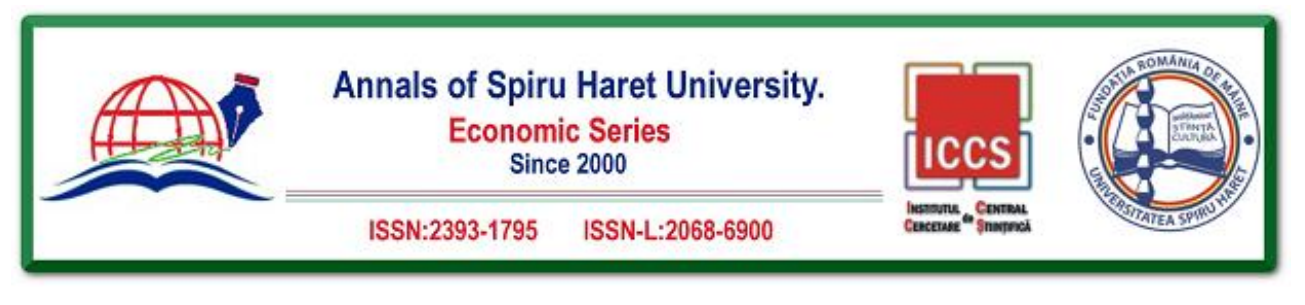

Issue $3 / 2018$

suppliers, if technology is high and profitable, quality, diversity and adaptability of products and services are special.

\section{References}

1. Campbell D. J., Craig T. Organisations and the Business Environment. Elsevier Butterworth-Heinemann, 2005.

2. Duro, R. B. Winning the Marketing War. John Wiley and Sons, 1989.

3. Doval, E. (2017). Change management strategies related to the global environment complexity, Annals of Spiru Haret University. Economic Series, ISSN 2393-1795, Issue 4/2016, p.35-42.

4. Fernando A. C. Business Environment. Pearson Education India, 2011.

5. Hall, W. K. (1980). Survival Strategies in a Hostile Environment. Harvard Business Review, Sept.-Oct.

6. Hammermesh, R. G. Silk, S. B. (1979). How to Compete in Stagnant Industries. Harvard Business Review, Sept.-Oct.

7. Morrison, J. The International Business Environment. Basingstoke, Palgrave, 2002.

8. Porter, M. E. Competitive Advantage. New York: The Free Press, 1985.

9. Porter, M. E. Competitive Strategy. The Free Press, New York, 1980.

10. Porter, M. E. Competition in Global Industries. Boston: Harvard Business School Press, 1986.

11. Ștefănescu, R. (2014a). Generic Company Strategies and Their Implications. Communication, Context, Interdisciplinarity Conference, Vol. 3, Petru Maior University Press.

12. Ștefãnescu, R. (2014b). Changes in the Global Business Environment Concerns Today's Competition. Globalization and Intercultural Dialogue. Multidisciplinary Perspectives Conference, Târgu-Mureș: Arhipelag XXI.

13. Ştefãnescu, R. (2009). Competitive Behaviour and Strategies in Business Environment. Calitatea - acces la success, vol. 10, nr. 101 special.

14. Negulescu, O. \& Doval, E., (2012). "Ethics Issues in the Management of the Projects." Review of General Management, Volume 15, Issue 1, pp. 36-43.

15. Negulescu, O. (2014). "Using a Decision-Making Process Model in Strategic Management." Review of General Management, Volume 17, Issue 1, pp. 111-123.

16. Petrova, E. \& Dimitrova, S. "European Citizens through Lifelong Learning." The 17th International Conference the Knowledge-Based Organization. Sibiu: Nicolae Balcescu Land Forces Academy, 2011, pp. 416-421.

17. Petrova, E. \& Nichev, N. "Impact of War on the Economy." International Conference the Knowledge-Based Organization. Sibiu: Nicolae Balcescu Land Forces Academy, 1416 June 2012, pp. 233-236. 


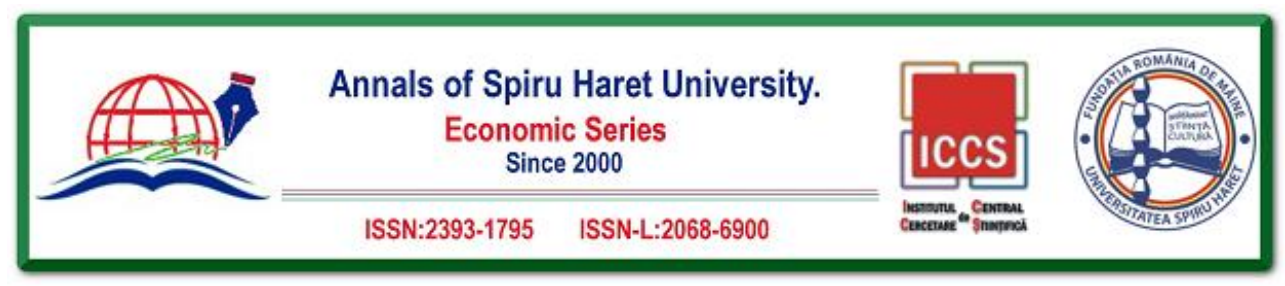

\section{Issue 3/2018}

18. Petrova, E. "Value Investing - Essence and Ways of Finding Undervalued Assets." The 21st International Conference the Knowledge-Based Organization, Sibiu: Nicolae Balcescu Land Forces Academy, 11-13 June 2015, pp. 344-348.

19. Petrova, E. Genesis of Strategic Management, 1st edition, bookboon.com, 2017. 